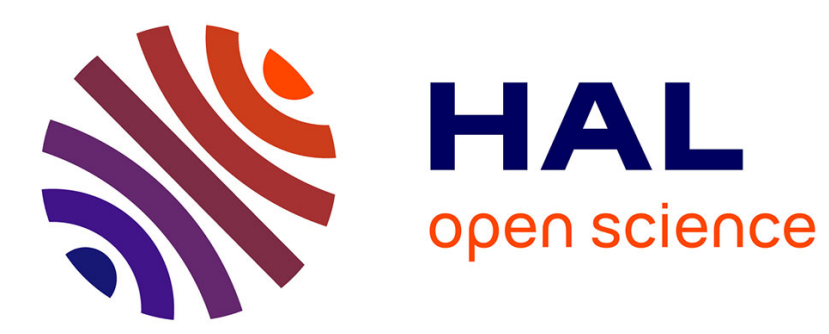

\title{
Discrete Event Model-Based Approach for Fault Detection and Isolation of Manufacturing Systems
}

Alexandre Philippot, Moamar Sayed-Mouchaweh, Véronique Carré-Ménétrier

\section{To cite this version:}

Alexandre Philippot, Moamar Sayed-Mouchaweh, Véronique Carré-Ménétrier. Discrete Event ModelBased Approach for Fault Detection and Isolation of Manufacturing Systems. 2nd IFAC Workshop on Dependable Control of Discrete Systems, Jun 2009, BARI, Italy. hal-02337864

\section{HAL Id: hal-02337864 \\ https://hal.science/hal-02337864}

Submitted on 29 Oct 2019

HAL is a multi-disciplinary open access archive for the deposit and dissemination of scientific research documents, whether they are published or not. The documents may come from teaching and research institutions in France or abroad, or from public or private research centers.
L'archive ouverte pluridisciplinaire HAL, est destinée au dépôt et à la diffusion de documents scientifiques de niveau recherche, publiés ou non, émanant des établissements d'enseignement et de recherche français ou étrangers, des laboratoires publics ou privés. 
See discussions, stats, and author profiles for this publication at: https://www.researchgate.net/publication/289883734

\section{Discrete event model-based approach for Fault Detection and Isolation of manufacturing systems}

Article $\cdot$ January 2009

CITATIONS

3

3 authors:

Alexandre Philippot

Université de Reims Champagne-Ardenne

79 PUBLICATIONS 202 CITATIONS

SEE PROFILE

Véronique Carré-Ménétrier

Université de Reims Champagne-Ardenne

61 PUBLICATIONS 236 CITATIONS

SEE PROFILE
READS

28

M. Sayed Mouchaweh

Institut Mines-Télécom Lille Douai

128 PUBLICATIONS 827 CITATIONS

SEE PROFILE

Some of the authors of this publication are also working on these related projects:

Project DICOLO - Dlagnosis and COntrol of discrete events systems by LOgical constraints View project

Special Issue on " Advanced Soft Computing for Prognostic Health Management" View project 


\title{
Discrete Event Model-Based Approach for Fault Detection and Isolation of Manufacturing Systems
}

\author{
A. Philippot, M. Sayed-Mouchaweh, V. Carré-Ménétrier \\ Université de Reims Champagne-Ardenne - Centre de Recherche en STIC (URCA-CReSTIC) \\ Moulin de la Housse B.P. 1039, 51687 REIMS Cedex 2, FRANCE, \\ (\{alexandre.philippot, moamar.sayed-mouchaweh, veronique.carre\}@univ-reims.fr)
}

\begin{abstract}
This paper presents a discrete event model-based approach for Fault Detection and Isolation of manufacturing systems. This approach considers a system as a set of independent plant elements. Each plant element is composed of a set of interrelated Parts of Plant (PoPs) modeled by a Moore automaton. Each PoP model is only aware of its local behavior. The degraded and faulty behaviors are added to each PoP model in order to obtain extended PoP ones. An extrapolation of Gaussian learning is realized to obtain acceptable temporal intervals between the time occurrences of correlated events. Finally based on the PoP extended models and the links between them, a fault candidates' tree is established for each plant element. This candidates' tree corresponds to a local on-line fault event occurrence observer, called diagnoser. Thus, the diagnosis decision is distributed on each plant element. An application example is used to illustrate the approach.
\end{abstract}

Keywords: Discrete-Event Systems, Decentralised/Distributed Models, Diagnosis, Automata, Manufacturing Systems.

\section{INTRODUCTION}

In complex systems, such as manufacturing processes, unpredictable events and undesired reactions are the consequence of the occurrences of faults. The later reduces significantly the systems performances. Manufacturing systems can be represented as Discrete Event Systems (DES), i.e., dynamic systems with discrete state spaces and eventdriven transitions (Cassandra et al. 1999). Consequently, Boolean information is only available and its observation alone does not often allow to detect the fault occurrences and to isolate the responsible elements.

Several approaches have been developed to solve the Fault Detection and Isolation (FDI) problem (Darkhovski et al. 2003, Hadjicostis 2005, Rozé et al. 2002). FDI has become a crucial issue for industrial process diagnosis leading to increase availability, reliability and production safety. FDI approaches can be divided generally into knowledge-based and model-based ones. The knowledge-based, or modelreasoning, approaches construct a model about the system behavior based on an initial human experience, e.g. expert systems, on a set of historical data, e.g. pattern recognition and signal processing methods (Duda 2001). Model-based FDI approaches compare a mathematical and/or graphical (automata, Petri nets, ...) model of the normal and/or abnormal behaviors of the system with its real input/output data. These models observe the system by their events in order to infer the fault occurrences. Thus, they are called “diagnosers" (Lamperti et al. 2008, Rozé et al. 2002).

Different structures of model-based approaches for diagnosing DES exist. The first structure is the centralized one which requires a global model of the system function as well as a global diagnoser (Sampath 1995). Constructing a global model is often intractable because of the complexity and the large size of the manufacturing systems. An alternative of the centralized structures is the componentoriented model approaches. In these approaches, the system global model is described by a set of local models available through a library. This description is realized by decentralized or distributed ways. In decentralized approaches (Wang et al. 05), the diagnosis is performed based on a set of local diagnosers. However, a global model of the system is required to take into account the links between the interrelated components. In distributed approaches (Boel et al. 2004, Philippot et al. 2007, Cordier et al. 2007), no need to global model. Each local model is only aware of its own behavior. The links, or dependencies, among components are considered via components exchange local diagnoses using communication protocols (Genc et al. 2003) or merging strategies (Cordier et al. 2007).

This paper proposes a modular and distributed FDI modelbased approach for plant faults detection and isolation of manufacturing systems. This approach divides the plant into a set of Parts of Plant (PoPs). A PoP can be an actuator or a sensor. They are modeled by discrete models which take into account the technology specifications used to produce them. Potential degraded and faulty behaviors of each PoP are added to its model in order to obtain an extended PoP model. Faulty behavior causes the production halt while the degraded one disturbs or reduces the optimal production performances. The PoP models are grouped into subsets of interrelated ones. Each subset of interrelated PoP models defines an independent plant element. Finally, the possible 
candidates for a faulty or degraded behavior of each plant element are established based on its own extended PoP models and the links between them.

The paper is structured as follows. In section 2, the proposed model-based FDI approach is presented. The system model is described by its PoP models included in a library. The later contains a set of local models of PoPs commonly used in discrete manufacturing systems. In section 3, a manufacturing system is used to illustrate the approach. The last section concludes the paper and presents future research directions.

\section{MODEL-BASED FDI APPROACH}

\subsection{Part of Plant}

Generally, plant is composed of pre-actuators, actuators and sensors (Fig. 1). We consider the plant as a set of independent plant elements $\mathrm{PE}_{\mathrm{k}}, \mathrm{k} \in\{1,2, . ., m\}$. Each plant element is composed of a set of actuators and sensors. Each actuator or sensor is defined as a Part of Plant (PoP). A PoP can react to failure events by changing its state.

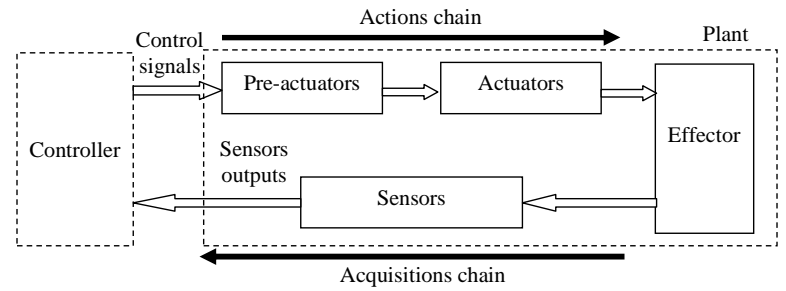

Fig. 1. Manufacturing system general structure.

We establish detailed PoP models which take into account the technological specifications (Deluche 1998) used to produce them. The goal is to obtain realistic models and to avoid combinatory explosion of DES modeling (Sampath 1995, Wonham et al. 1987). Each model is represented by a Moore automaton (Cassandra et al. 1999). The later is a Finite State Machine (FSM) in which the outputs are determined by the current state. Each PoP local model receives failure and internal events and emits its internal events and state outputs to the other interrelated PoPs.

A PoP model is represented by timed Moore automaton defined as a 11-tuple $G_{P o P}=\left(Q, q_{0}, \Sigma, \Lambda, T, O, Q^{*}, T_{s}, \Delta, t\right.$, $\Psi)$ where:

- $Q$ is a finite set of static states ;

- $q_{0}$ is the initial state belonging to $Q$;

- $\quad \Sigma$ is a finite set of input events (input alphabet) ;

- $\Lambda$ is a finite set of output events (output alphabet) ;

- $(T: Q \times \Sigma \rightarrow Q)$ is a transition function mapping a state and the input alphabet to the next state ;

- $(O: Q \rightarrow \Lambda)$ is an output function mapping each state to the output alphabet ;

- $Q^{*}$ is a finite set of dynamic states (represented in dotted line in Table 1);
- $\left(T_{s}\right)$ is a Time of stroke required for the displacement between two positions (transition between two states);

- $\Delta$ is a time variable of temporary allocation ;

- $t$ is a local clock measuring the elapsed time between 2 events ;

- $\Psi=\{->,:=\}$ is a finite set of operands. (->) and $(:=)$ refer, respectively, to allocation and equality test operations.

Table 1. Library of commonly used Part of Plant models in discrete manufacturing systems

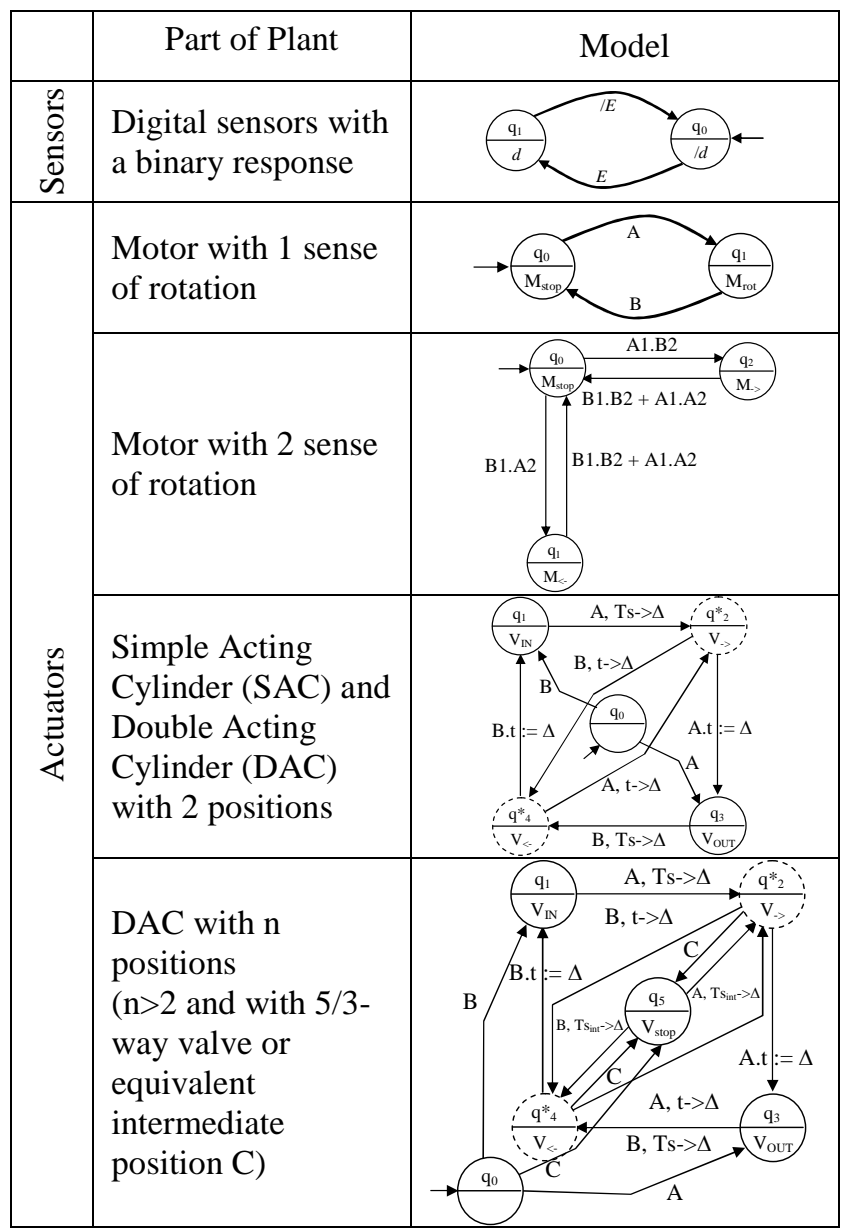

The construction steps of PoP models are described in (Philippot et al. 2008) and can be resumed in Table 1. As an example, let consider the model GDAC of the Double Acting Cylinder (DAC) with 2 positions. The model GDAC evolves from its initial state $\mathrm{q} 0$ towards the states $\mathrm{q}_{1} / \mathrm{VIN}$ or $\mathrm{q}_{3} /$ VOUT according, respectively, to the activation of the control signals $\mathrm{B}=$ In or $\mathrm{A}=$ Out. The states $\mathrm{q}_{1} / \mathrm{VIN}$ and $\mathrm{q}_{3} /$ VOUT represent, respectively, the piston rod in home return and in fully extended positions indicated, respectively, by the output events VIN and VOUT. If the model is located in the state $\mathrm{q}_{1}$, the activation of the control signal $\mathrm{A}=$ Out leads the piston rod to move forward. This piston rod movement is represented by the dynamic state $q^{*} / \mathrm{V}->$. The output event $\mathrm{V}->$ indicates that the piston rod is in movement towards its fully extended position. The time required to reach this position, Ts, is assigned to the time variable $\Delta$. In the same time, a local clock $\mathrm{t}$ is initiated to calculate the spent time 
during the forward movement. At this dynamic state, two cases can arise. In the first case, the value of $t$ becomes equal to the one allocated to $\Delta$. This means that the actuator has reached its fully extended position. Therefore, GDAC reaches the state q3 with the output event Vout. In the second case, the control signal $\mathrm{B}=\mathrm{In}$ is activated. This activation forces the piston rod to stop moving forward in order to inverse its movement towards its home position. Thus, GDAC evolves to the dynamic state $\mathrm{q} * 4$ with the output event $\mathrm{V}<$ - indicating that the piston rod is in inversed movement. In this case, the present spent time $\mathrm{t}$ is assigned to $\Delta$. Then, the local clock is initiated again to calculate the elapsed time in the inverse movement. When this time becomes equal to the one allocated to $\Delta$, the piston reaches its home position indicated by the state $\mathrm{q} 1 / \mathrm{VIN}$. The same reasoning can be followed for the other states.

\subsection{Abnormal or faulty states}

We adopt the hypothesis that each behavior which does not correspond to a normal one is considered as abnormal one. Thus, starting from normal states of each PoP model, it is possible to determine the abnormal (degraded or faulty) states. An abnormal state is reached due to the occurrence of a failure event, which is unobservable event, at a normal state. The abnormal states are represented by a square in the extended PoP models. For the example of the DAC with 2 positions, these abnormal states indicate the following faults:

- $\quad$ The DAC is stuck or blocked (B) ;

- The DAC reacts too slowly to the control signals in comparison with its normal behavior (D).

However, these abnormal states require the determination of the intervals defining the acceptable time displacement of the DAC. To determine these intervals, we have established a learning phase about the system's normal and abnormal behaviors. The goal of this learning is to obtain realistic time response intervals related to the system dynamic and to the PoP technology. These intervals are obtained by an extrapolation of Gaussian learning defining the probability, chance, of the occurrence of an event in this interval. The temporal constraints between the time occurrences of correlated events can then be represented by a template (Holloway et al. 1994) or a chronicle (Cordier et al. 2000).

We use the Balemi's interpretation. In (Balemi et al. 1993), the authors define controllable events $\Sigma_{\mathrm{c}} \subseteq \Sigma$ as controller's outputs sent to actuators, and uncontrollable events $\Sigma_{\text {uc }} \subseteq \Sigma$ as the controller's inputs coming from sensors. $\Sigma_{\mathrm{o}}=\Sigma_{\mathrm{c}} \cup \Sigma_{\mathrm{uc}}$ is the set of observable events and is included in $\Sigma$. It considers that a change of a variable $\alpha$ from 0 to 1 , or from 1 to 0 produces events characterized by either rising, $\uparrow \alpha$, or falling edges, $\downarrow \alpha$. Consequently, the observation of the system's, actuators, reactivity is achieved by these sensors events, which are considered as uncontrollable events. The control events, produced by the activation of control signals, are considered as controllable events. The use of rising and falling edges facilitates the detection of permanent and intermittent faults.

\subsection{Plant Elements}

The plant of a system is composed by $n$ Parts of Plant: $\mathrm{PoP}_{\mathrm{i}}, \mathrm{i}$ $\in\{1,2 \ldots n\}$. Each local $\mathrm{PoP}_{\mathrm{i}}$ is modelled by 11 -tuple $G_{P o P i}=$ $\left(Q_{i}, q_{0 i}, \Sigma_{i}, \Lambda_{i}, T_{i}, O_{i}, Q_{i}^{*}, T_{s i}, \Delta_{i}, t_{i}, \Psi_{i}\right)$ as defined section 2.1. A plant element $\mathrm{PE}_{\mathrm{k}}$ is said to be "independent" of another one $\mathrm{PE}_{\mathrm{h}}$ if their models do not have common inputs and outputs events. Consequently, each independent plant element contains an independent subset of PoPs from the other plant elements. If $\left\{\mathrm{PoP}_{\mathrm{PE}_{\mathrm{k}}}\right\}$ denotes the set of PoPs constituting the Plant Element $P E_{\mathrm{k}}$, then plant elements independency can be represented by:

$$
\forall \mathrm{PoP}_{\mathrm{i}} \in\left\{\mathrm{PoP}_{\mathrm{PE}_{\mathrm{k}}}\right\}, \forall \mathrm{PoP}_{j} \in\left\{\mathrm{PoP}_{\mathrm{PE}_{\mathrm{h}}}\right\} \Rightarrow\left[\begin{array}{l}
\Sigma_{\mathrm{PoPi}} \cap \Lambda_{\mathrm{PoP}_{\mathrm{j}}}=\Phi \\
\Lambda_{\mathrm{PoPi}_{i}} \cap \Sigma_{\mathrm{PoP}_{j}}=\Phi
\end{array}\right.
$$

No need to construct a global model of a system if it is divided into a set of independent plant elements. The occurrence of a fault in a PoP belonging to a plant element will not be propagated to other plant elements. However, a plant element can possess relatively a big number of PoPs in order to be independent of the other plant elements. This depends of system and its structure. In the worst case, a system can be divided into one plant element if all the PoPs are interrelated.

\subsection{Fault Plant Element Candidates}

The candidates responsible of the occurrence of a fault in a PE can be determined based on its PoP models as well as on its temporal constraints represented by a set of templates or chronicles. The following two hypotheses are considered:

- Only one failure event responsible of a faulty or degraded behavior can occur at the same time ;

- Controller is supposed to be dependable and safety. Consequently, the controller cannot be responsible of any fault as the one of sending two opposable control signals.

Now, to determine all possible candidates responsible of an abnormal behavior in a Plant Element, a candidates' tree is constructed. It is based on a knowledge expert and on each control signal sent by the controller. A control signal entails only one Plant Element of the system to evolve. The response of this control signal is sensors' events leading to change their outputs. Consequently, the abnormal states can be calculated according to these outputs.

The number of candidates can be reduced using a progressive monitoring. The occurrence of new sensors events can lead to eliminate the improbable or inconsistent candidates with this new observation. The fault candidates' tree can correspond to an online diagnoser which returns one or several labels according to the observations. Furthermore, thanks to the results of Gaussian learning, it is possible to achieve a preference, i.e., more probable candidates for the occurrence of a fault. This preference is considered by the order of labels, i.e. candidates, in each state of the candidates' tree. 


\section{MANUFACTURING SYSTEM EXAMPLE}

To illustrate the proposed approach, we use the example of pick and place station of the flexible manufacturing system platform Cellflex (http://meserp.free.fr/). This station realizes the import and the export of pieces by a gripper between two processes thanks to a pneumatic system on 3 axes (Fig. 2). The symbol " 1 " refers to $Z$ axis displacement, " 2 " to $X$ axis displacement, "3" to $Y$ axis displacement and "4" to the pneumatic system gripper.

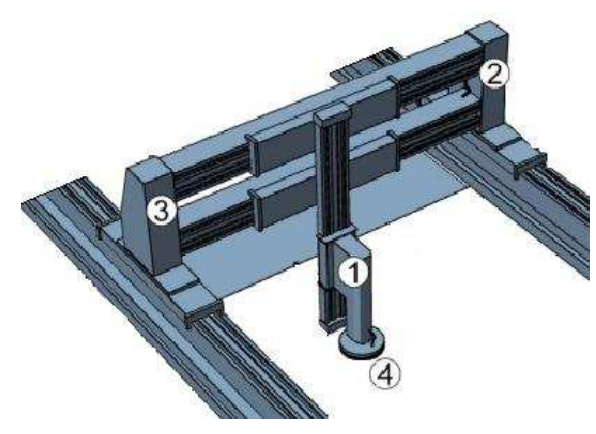

Fig. 2. Pick and place station

This station is composed of 4 actuators piloted by 6 preactuators produced by different technologies. The information about the behavior of the station is provided by 9 sensors (Fig. 3). These models have been constructed using the software Stateflow of Matlab ${ }^{\circledR}$ in order to generate their behavior by simulation.

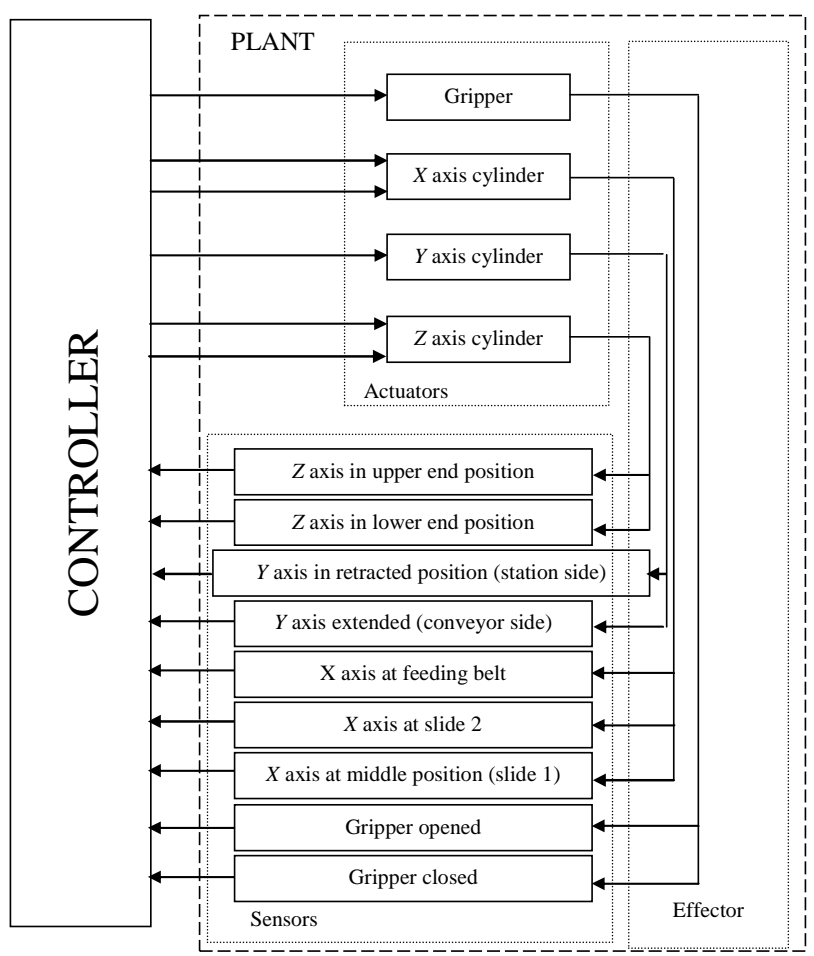

Fig. 3. PoP of pick and place station

\subsection{PoP of $Y$ axis PE}

Based on Fig. 3, we can see the interactions between PoPs allowing gathering them in independent Plant Elements (PEs). For example, the $Y$ axis is composed of 3 PoPs (one actuator and 2 sensors) which communicate among them. The actuator is a Double Acting Cylinder (DAC) where its retracted and extended positions are indicated by, respectively, the sensors $y_{R}$ and $y_{E}$. These 3 interrelated PoPs constitute the " $Y$ axis" PE. We keep this PE for the explanations hereafter (Fig. 4).
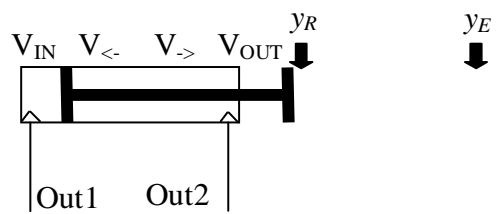

Fig. 4. Plant Element of $Y$ axis

The Fig. 5 and Fig. 6 illustrate the determination of all possible abnormal states. For example, when the state $\mathrm{q}_{0}$ of the PoP sensor $y_{R}$ model is active, (Fig. 5), the retracted position sensor can be blocked $\left(\mathrm{B}_{\mathrm{y} \mathrm{YR}}\right)$. For the the DAC model (Fig. 6), starting from the initial state $\mathrm{q}_{0}$ and in function of the inputs, the DAC model evolves towards states $\mathrm{q}_{1} / \mathrm{V}_{\mathrm{IN}}$ or $\mathrm{q}_{3} / \mathrm{V}_{\text {OUT }}$. At the state $\mathrm{q}_{1} / \mathrm{V}_{\mathrm{IN}}$, representing the piston rod in completely retracted position, the cylinder can be blocked in forward direction $\mathrm{B}_{\text {Vout }}$. At the state $\mathrm{q}_{3} / \mathrm{V}_{\text {OUT }}$, the cylinder can be blocked in backward direction $\mathrm{B}_{\mathrm{Vin}}$. All possible abnormal states of the " $Y$ axis" PE is classified in Table 2.

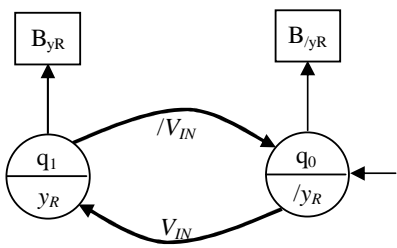

a) Sensor $y_{R}$ abnormal events

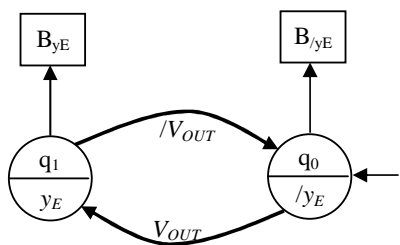

b) Sensor $\mathrm{y}_{\mathrm{E}}$ abnormal events
Fig. 5. Determination of sensors $y_{R}$ and $y_{E}$ abnormal states

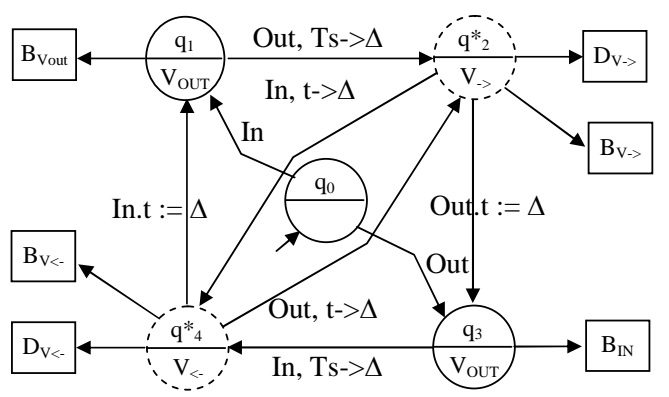

Fig. 6. Determination of DAC abnormal states 
Table 2. Classification of abnormal events

\begin{tabular}{|c|c|c|}
\hline Type & Label & Description \\
\hline \multirow{8}{*}{ 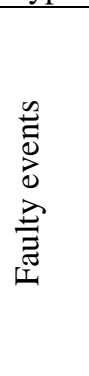 } & $\mathrm{B}_{\mathrm{yR}}$ & sensor $y_{R}$ blocked at 1 \\
\hline & $\mathrm{B}_{/ \mathrm{yR}}$ & sensor $y_{R}$ blocked at 0 \\
\hline & $\mathrm{B}_{\mathrm{yE}}$ & sensor $y_{E}$ blocked at 1 \\
\hline & $\mathrm{B}_{/ \mathrm{yE}}$ & sensor $y_{E}$ blocked at 0 \\
\hline & $\mathrm{B}_{\text {Vin }}$ & DAC blocked in retracted direction \\
\hline & $\mathrm{B}_{\mathrm{V}->}$ & DAC blocked during forward movement \\
\hline & $\mathrm{B}_{\text {Vout }}$ & DAC blocked in extended direction \\
\hline & $\mathrm{B}_{\mathrm{V}<-}$ & $\begin{array}{l}\text { DAC blocked during backward } \\
\text { movement }\end{array}$ \\
\hline \multirow{2}{*}{ 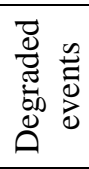 } & $\mathrm{D}_{\mathrm{V}->}$ & $\begin{array}{l}\text { DAC too slowly acting in extended } \\
\text { direction }\end{array}$ \\
\hline & $\mathrm{D}_{\mathrm{V}<-}$ & $\begin{array}{l}\text { DAC too slowly acting in retracted } \\
\text { direction }\end{array}$ \\
\hline
\end{tabular}

\subsection{Extrapolation of Gaussian learning}

The " $Y$ axis" PE can be represented as a block for which the inputs are the control signals of the controller, In and Out, and the outputs are the sensors' information, $y_{R}$ and $y_{E}$ (Fig. 7). The controller is supposed to be safety and dependable. Consequently, it is not possible to have the activation of In and Out at the same time. When the control signal Out is activated, the normal response is $\downarrow y_{R}$ followed by $\uparrow y_{E}$. A learning of all sensors' outputs' events can be achieved. For example, Fig. 8 presents the learning of $\uparrow y_{E}$ after the activation of Out. Fig. 9 presents the extrapolation of Gaussian learning when the command Out is activated. This activation expects as normal response the sensors events $\downarrow y_{R}$ and $\uparrow y_{E}$ within, respectively, the time intervals $\delta_{1}$ and $\delta_{2}$. Any other response to this control signal activation will be considered as abnormal behavior. A tolerance interval $\delta_{3}$ is added to $\delta_{1}$ and $\delta_{2}$, in order to take into account the delay in events' occurrences. This interval is subjective and represents about 25 per cent of $\delta_{2}$. In the next paragraph, the fault candidates' tree is constructed for the " $Y$ axis" PE after the activation of a control signal.

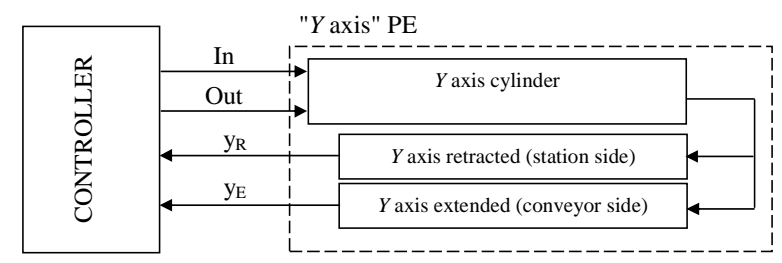

Fig. 7. Observable events of the " $Y$ axis" PE

\subsection{Candidates for the diagnosis of the " $Y$ axis" PE}

To define the fault candidates for a PE after the activation of each control signal, all the events consequences are analyzed based on the PoP extended models and their links. For example, Fig. 10 presents the fault candidates' tree after the activation of Out for the "Y axis" PE. If the time delay occurrence of $\downarrow y_{R}$ belongs to $\delta_{1}$ and the one of $\uparrow y_{E}$ to $\delta_{2}$, then the behavior is considered as normal and the returned label is $\mathrm{N}$ (state $\mathrm{q}_{10}$ ). While if this delay time occurrence of $\downarrow \mathrm{y}_{\mathrm{R}}$ and the one of $\uparrow y_{\mathrm{E}}$ belong, respectively, to $\delta_{1}$ and $\delta_{3}$ (state $\mathrm{q}_{11}$ ), then the behavior is degraded and the candidate is: too slowly acting DAC in comparison with its normal displacement velocity (DV->). While if the delay time occurrence of $\downarrow y_{R}$ belongs to $\delta_{1}$ and the one of $/ \mathrm{y}_{\mathrm{E}}$ is greater than $\delta_{3}$, then the fault candidates are $\left\{\mathrm{B} / \mathrm{y}_{\mathrm{E}}, \mathrm{BV}->\right\}$ (state $\mathrm{q} 12$ ). However, Gaussian learning indicates that $\mathrm{B} / \mathrm{y}_{\mathrm{E}}$ is more probable than $\mathrm{BV}->$. These fault candidates are proposed to the user in order to facilitate his task of making decision about the system behavior status. The generation of the other candidates' in response to the other control signals activation is achieved similarly.

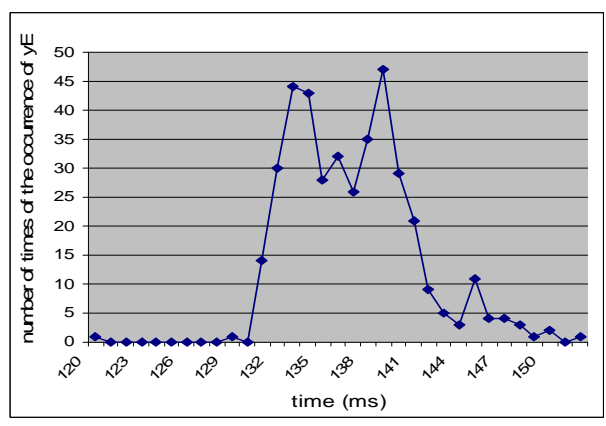

Fig. 8. Learning of the interval of occurrence of the event $\uparrow y_{E}$ as well as its probability after the activation of Out

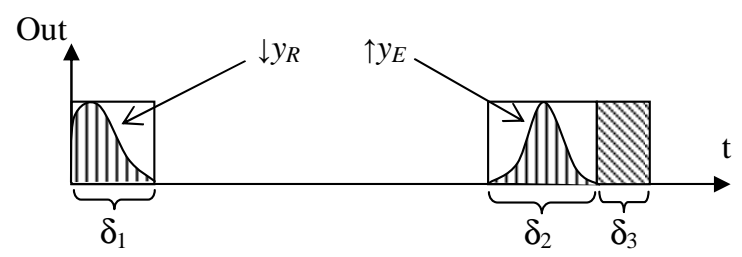

Fig. 9. Extrapolation for the sensors events occurrences intervals after the activation of the control signal Out

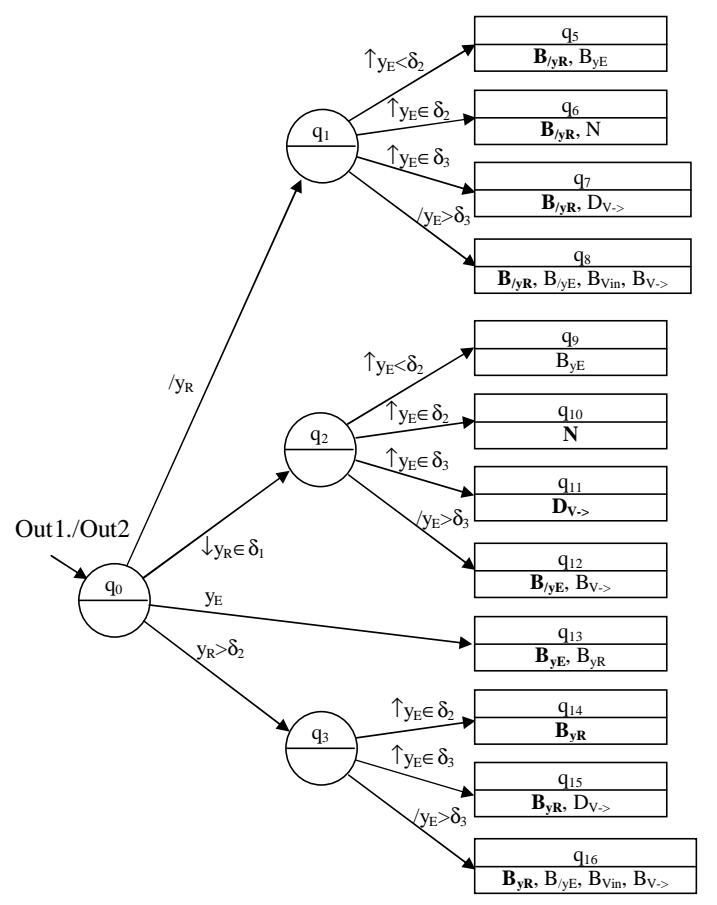

Fig. 10. Fault candidates' tree for the " $Y$ axis" $P E$ after the activation of Out 


\subsection{Remarks}

Candidates' tree is only information on the system behaviour. It corresponds to a proposition to the user which is the only one who can take a decision. Consequently, it is used on-line when a command is sent and reinitialized from another command if the behaviour is normal or by the user for an abnormal behaviour.

\section{CONCLUSIONS AND FUTURE WORKS}

This paper presents a model-based Fault Detection and Isolation (FDI) approach for the diagnosis of discrete manufacturing system. The global model of the system is described by a set of independent plant elements. Each one of the later is composed of a set of interrelated parts of plant. A part of plant can be an actuator or a sensor. The diagnosis is thus distributed on each element plant.

However, only the faults related to PoPs (actuators and sensors) are considered. To take into account the product faults, a product model is necessary. This model depends on the product nature and on the production objective. Thus, a future work is to extend this approach to include the faults related to products. Another perspective is to extend the PoP library by integrating a new family of PoPs with their preactuators. The goal is to obtain more realistic plant model.

\section{ACKNOWLEDGEMENTS}

This work is integrated in the project MOSYP (Performances Measurements and Optimization of Production Systems). The authors would like to thank the region Champagne-Ardennes within the project MOSYP (CPER ICOS).

\section{REFERENCES}

Balemi, S., Hoffmann, G.J., Gyugyi, P., Wong-Toi, H. and Franklin G.F. (1993). Supervisory control of a rapid thermal multiprocessor. IEEE Transactions on Automatic Control, vol. 38, N7, pp.1040-1059.

Boel, B.K. and Jiroveanu G. (2004). Distributed contextual diagnosis for very marge systems. $7^{\text {th }}$ International Workshop on Discrete Event Systems WODES'04, pp.343-348, Reims, France.

Cassandra, C.G. and Lafortune, S. (1999). Introduction to Discrete Event Systems. Kluwer Academic Publisher, ISBN 0792386094.

Chandra, V. and Kumar, R. (2001). A Discrete Event Systems Modeling Formalism Based one Event Occurrences Rules and Precedences. IEEE Transactions on Robotics and Automation, vol. $17, \mathrm{n}^{\circ} 6$.

Cordier, M.O. and Dousson, C. (2000). Alarm driven monitoring based on chronicles. Proceedings of Safeprocess'2000, pp. 286-291, Budapest, Hungary.

Cordier, M.O. and Grastien, A. (2007). Exploiting Independence in a Decentralised and Incremental. 20th International Joint Conference on Artificial Intelligence, pp. 292-297.
Darkhovski, B. and Staroswiecki, M. (2003). Theoretic Approach to Decision in FDI. IEEE Transactions on Automatic Control, vol. 48, n 5 .

Deluche, J.B. (1998). Automatique de la théorie aux applications industrielles. Tome 1 : Systèmes discrets. Edipol - Collection Instrumentation, ISBN 2913444008.

Genc, S. and Lafortune, S. (2003). Distributed diagnosis of discrete-event systems using Petri nets. International Conference on Application and Theory of Petri Nets, pp. 316-336, Eindhoven, The Netherlands.

Hadjicostis, C.N. (2005). Probabilistic Fault Detection in Finite-State Machines Based on State Occupancy Measurements. IEEE Transactions on Automatic Control, vol. $50, \mathrm{~N}^{\circ} 12$, pp. 2078-2083.

Holloway, L.E. and Chand, S. (1994). Time templates for discrete event fault monitoring in manufacturing systems. American Control Conference, Baltimore, USA.

Lamperti, G., Zanella, M. (2008). On Processing Temporal Observations in Monitoring of Discrete-Event Systems. Book Chapter, Enterprise Information Systems: Part 3, vol. 3, pp.135-146, ISBN 978-3-540-77580-5.

Machado, J. (2006). Influence de la prise en compte d'un modèle de processus en vérification formelle des systèmes à événements discrets. Thèse de l'Ecole Normale Supérieure de Cachan, Cachan, France.

Duda, R. O., Hart, P. E.,. Stork D. G, (2001). Pattern Classification $2^{\text {nd }}$ edition. Wiley-Interscience.

Philippot, A., Sayed-Mouchaweh, M. and Carré-Ménétrier, V. (2007). Unconditional Decentralized Structure for the fault diagnosis of Discrete Event Systems. $1^{\text {st }}$ IFAC Workshop on Dependable Control of Discrete-event Systems (DCDS'07), Cachan, France.

Philippot, A., Sayed-Mouchaweh, M. and Carré-Ménétrier, V. (2008). Nouvelle modélisation de Partie Opérative pour systèmes manufacturiers. Conférence Internationale Francophone d'Automatique (CIFA'08), Bucarest, Romania.

Qiu, W. (2005). Decentralized/distributed failure diagnosis and supervisory control of discrete event systems. PhD of the Iowa State University, USA.

Rohée, B., Riera, B., Carré-Ménétrier, V. and Roussel, J.M. (2006). A methodology to design and Check Plant Model. $3^{r d}$ IFAC Workshop on Discrete-Event System Design (DESDes06), Rydzyna, Pologne.

Rozé, L. and Cordier, M.O. (2002). Diagnosing DiscreteEvent Systems: Extending the "Diagnoser Approach" to Deal with Telecommunication Networks. In Discrete Event Dynamic Systems, vol. 12, n 1, pp.43-81, ISSN 0924-6703.

Sampath, M. (1995). A Discrete Event Systems Approach to Failure Diagnosis. Thesis, University of Michigan, Michigan, USA.

Wang, Y., Yoo, T.S. and Lafortune S. (2005). Decentralized diagnosis of discrete event systems using conditional and unconditional decisions. Proceeding of CDC'05, $44^{\text {th }}$ IEEE Conference on Decision and Control.

Wonham, W. M. and Ramadge, P.J. (1987). On the supremal controllable sublanguage of a given language. SIAM Journal on Control and Optimization, vol. 25, n³, pp.637-659. 